\title{
STUDIES IN THORACIC AORTIC GRAFT INFECTIONS: THE DEVELOPMENT OF A PORCINE MODEL AND A COMPARISON OF COLLAGEN-IMPREGNATED DACRON GRAFTS AND CRYOPRESERVED ALLOGRAFTS
}

Norman M. Rowe, MD

Paul Impellizzeri, $\mathrm{MMS}^{\mathrm{a}}$

Mikhail Vaynblat, MD

Nuria M. Lawson, MD

Yoon D. Kim, $\mathrm{MD}^{\mathrm{b}}$

Marcel Sierra, $\mathrm{PhD}^{\mathrm{c}}$

Peter Homel, $\mathrm{PhD}^{\mathrm{d}}$

Anthony J. Acinapura, MD ${ }^{\mathrm{a}}$

Joseph N. Cunningham, Jr, MD

Joshua H. Burack, MDa
Objective: A porcine model of thoracic aortic graft infection was created, and various anatomic sites and the timing of inoculation of the graft to induce infection were investigated. Ultimately, the ability of cryopreserved allograft to resist infection was compared with that of collagenimpregnated Dacron graft. Methods: Yorkshire pigs $(n=16)$ underwent placement of an expanded polytetrafluoroethylene patch graft in the ascending aorta and the left atrial appendage (phase I). Eight animals were immediately given a $50-\mathrm{mL}$ bolus $\left(1 \times 10^{8} \mathrm{cfu} / \mathrm{mL}\right)$ of Staphylococcus aureus whereas the other 8 received the infusion 24 hours later. Animals were put to death 8 weeks later and the grafts were sterilely explanted and analyzed via microbiologic culture and standard histologic procedures for evidence of infection. The results displayed that the aortic graft and a delay of induced bacteremia of 24 hours were more reliable methods of producing infection. During phase II, 13 pigs were randomized to receive either a collagen-impregnated Dacron graft $(n=6)$ or a cryopreserved allograft $(n=7)$ in the ascending aortic position only and infusion of $S$ aureus 24 hours after the operation. The experiment then proceeded to completion. Results: Phase I results displayed that use of an aortic graft and induced bacteremia 24 hours after the operation was a more reliable and reproducible method of producing infection. In phase II, graft infection was present in $38.5 \%(5 / 13)$ of animals, with only $16.7 \%(1 / 6)$ in the collagen-impregnated Dacron graft group and $57.2 \%$ (4/7) in the cryopreserved allograft group becoming infected. There was no significant difference between the collagen-impregnated Dacron graft and cryopreserved allograft groups in the incidences of thoracic aortic graft infections $(P=.27$, Fisher exact test). Conclusions: This novel porcine model of thoracic aortic graft infection is a reproducible method for the investigation of thoracic aortic graft infections. The phase I study investigated the timing of the induced bacteremia and the most susceptible position of a graft. Phase II demonstrated that collagen-impregnated Dacron grafts are equivalent, if not superior, to cryopreserved allografts in resisting central vascular graft infections in the ascending aorta. (J Thorac Cardiovasc Surg 1999;118:857-65)
$\mathrm{R}$ econstruction or replacement of structures in the heart and proximal aorta is widely used. A dangerous and challenging circumstance is present when the operation is performed during acute endocarditis or

From the Department of Surgery, ${ }^{a}$ Division of Cardiothoracic Surgery, Department of Pathology, ${ }^{\mathrm{b}}$ Department of Microbiology, ${ }^{\mathrm{c}}$ and Department of Biostatistics, ${ }^{\mathrm{d}}$ State University of New York, Health Science Center at Brooklyn, Brooklyn, NY.

Read at the Seventy-ninth Annual Meeting of The American Association for Thoracic Surgery, New Orleans, La, April 18-21, 1999.

Received for publication March 19, 1999; revisions requested April 29, 1999; revisions received July 6, 1999; accepted for publication Aug 11, 1999. when the site of surgical reconstruction is exposed to significant postoperative bacteremia. ${ }^{1}$ Infections of vascular prostheses after replacement of the thoracic aorta remain a rare but serious complication with a high mor-

\footnotetext{
Address for reprints: Joshua H. Burack, MD, State University of New York, Health Science Center at Brooklyn, Department of Surgery, Division of Cardiothoracic Surgery, 450 Clarkson Ave, Box 40, Brooklyn, NY 11203.
}

Copyright @ 1999 by Mosby, Inc.

$0022-5223 / 99 \$ 8.00+0 \quad \mathbf{1 2} / \mathbf{6} / \mathbf{1 0 2 0 8 4}$ 

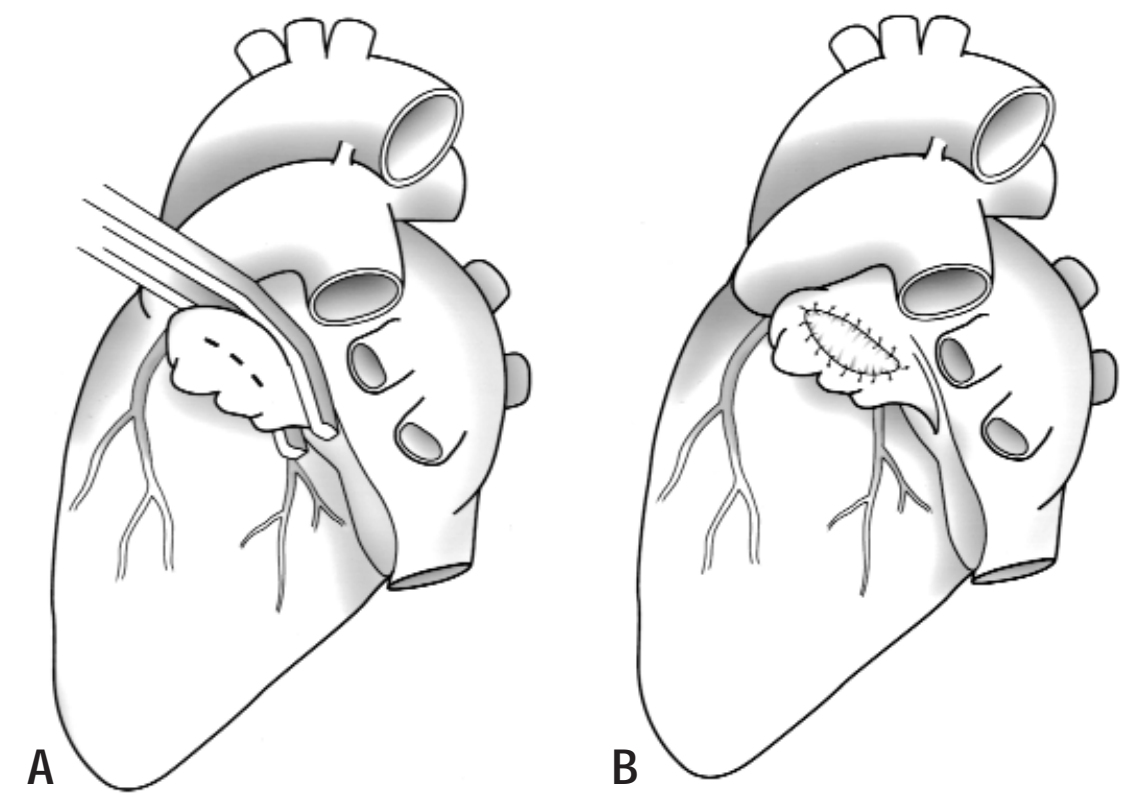

Fig 1. A, Occlusion of the base of the left atrial appendage with a vascular clamp (Satinsky) and resection of atrial wall $(1 \times 2 \mathrm{~cm})$. B, e-PTFE graft in place on the left atrial appendage.

tality. ${ }^{2,3}$ This condition arises after treatment of mycotic aneurysms, infected vascular grafts, catheter induced sepsis, and aortobronchial and aortoenteric fistulas. ${ }^{4}$ An ideal reconstruction or prosthesis would be highly resistant to endovascular infection.

Substantial clinical data support the intuitive concept that reconstruction with autogenous or homologous tissue will resist most bloodstream infections. ${ }^{5-7}$ These reports support the use of extra-anatomic revascularization with either simultaneous or staged removal of the entire contaminated prosthesis or the use of cryopreserved aortic homograft in the native position. ${ }^{8}$ This contrasts with the traditional operative approach to endocarditis and infectious endarteritis, which is based on reconstruction with synthetic material. Satisfactory surgical results, using the traditional technique of prosthetic replacement, have been repeatedly observed. ${ }^{9-11}$ However, this clinical information is not entirely conclusive and reflects varied human experience rather than controlled laboratory observation.

There is no animal model available with which to examine the surgical treatment of cardiac and proximal aortic infections. This is in contrast to the established infrarenal aortic graft infection preparation, which is relevant to abdominal aortic and peripheral vascular graft infections. ${ }^{12-14}$ These findings may not be applicable to the thoracic aorta because of the intrinsically different properties between the thoracic and abdominal aorta.
The goal of this study was to create a reproducible animal model for the study of central vascular graft infections. The porcine model was chosen because it appears to react to vascular infection in a similar fashion to human beings. ${ }^{15,16}$ During phase I of the study, the feasibility of the porcine model and the optimal positioning and timing of Staphylococcus aureus inoculation of a graft to induce infection were studied. Phase II consisted of a comparison of the ability of collagen-impregnated Dacron graft (CIDG) as compared with cryopreserved porcine allograft (CPA) to resist infection in the ascending aortic position.

\section{Materials and methods}

Animals. Immature Yorkshire pigs of similar ages (approximately 2-4 months) and sizes (15-20 kg) were acclimated to the SUNY-Brooklyn Research Facility surroundings and prepared for surgery according to the protocol approved by the SUNY-Brooklyn Institutional Animal Care and Use Committee in accordance with the "Guide for the Care and Use of Laboratory Animals" prepared by the Institute of Laboratory Animal Resources, National Research Council, and published by the National Academy Press, revised 1996. Each animal was sedated with ketamine hydrochloride (Ketaset) $2.0 \mathrm{mg} / \mathrm{kg}$ intramuscularly and xylazine hydrochloride 2.0 $\mathrm{mg} / \mathrm{kg}$ intramuscularly and then endotracheally intubated with a $6 \mathrm{~F}$ endotracheal tube after induction of anesthesia with sodium thiopental $5.0 \mathrm{mg} / \mathrm{kg}$. Inhalational anesthesia was maintained with halothane at a concentration of $0.5 \%$ to 

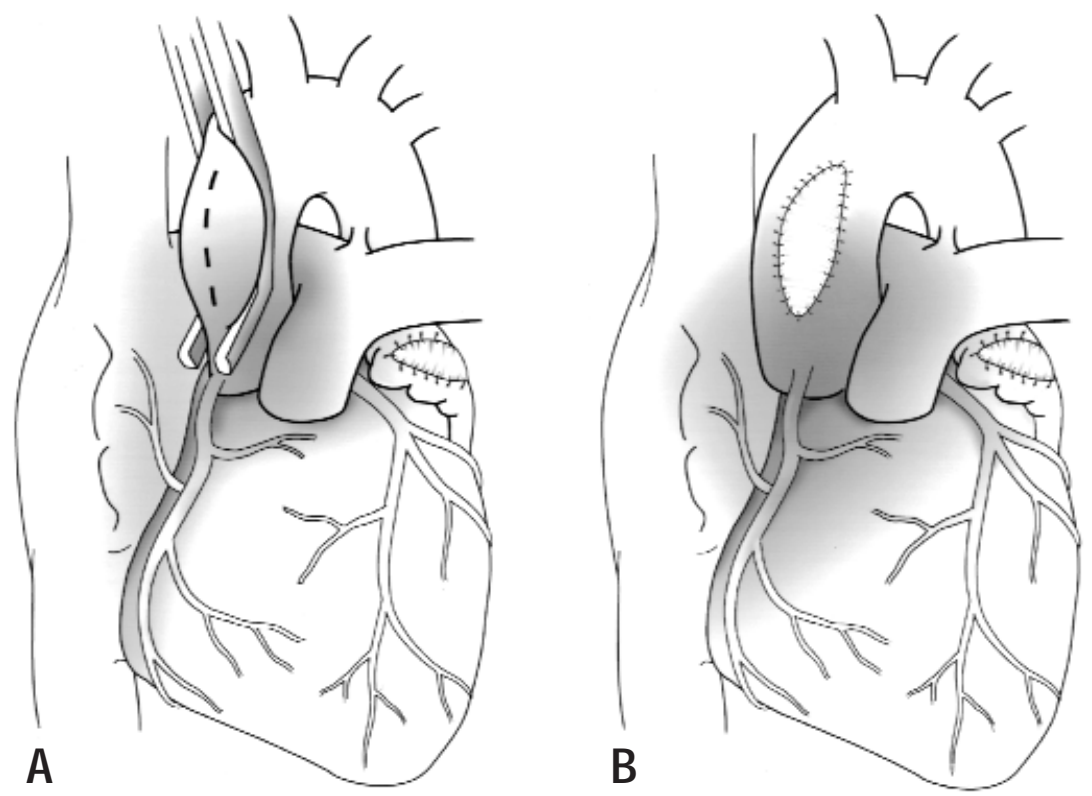

Fig 2. A, Partial occlusion vascular clamp (Satinsky) in place on the mid ascending aorta after which a segment of native aorta was resected $(1 \times 2 \mathrm{~cm})$. B, e-PTFE graft in place on the mid ascending aorta and left atrial appendage.

1.0\%. Femoral arterial pressure, electrocardiography, and pulse oximetry were continuously monitored.

Phase I: Studies in optimal positioning and time of inoculation of the graft. Sixteen animals were used to determine the optimal placement of grafts to be studied and the timing of the induced bacteremia. Each animal had a transverse sternotomy performed through the 4th intercostal space. The pericardium was then marsupialized and the animal given an infusion of heparin sodium (100 U/kg). The base of the left atrial appendage was transiently occluded with a vascular clamp (Satinsky), and a small segment $(1 \times 2 \mathrm{~cm})$ was resected (Fig 1, A). A similar size of expanded polytetrafluoroethylene (e-PTFE) graft ${ }^{*}$ was sutured in place over the defect with 6-0 e-PTFE suture and the clamp was then released (Fig 1, B).

A partial occlusion vascular clamp (Satinsky) was then placed transiently on the mid ascending aorta and a segment of native aorta was resected $(1 \times 2 \mathrm{~cm})$ (Fig 2,A). This was replaced with a similar size of e-PTFE graft material, again sutured in place with 6-0 e-PTFE suture over the aortic defect, and the partial occlusion clamp was released (Fig 2, $B)$. This is similar to the coarctation technique as described by Cooley. ${ }^{17}$ The pericardium, sternotomy, and the soft tissue were closed by means of standard techniques. The animal was awakened, extubated, and allowed to recover.

The 16 animals were then randomized into 2 groups. Group $1(\mathrm{n}=8)$ animals received a $50 \mathrm{~mL}$ intravenous bolus of $S$ aureus $\left(1 \times 10^{8}\right.$ colony forming units $\left.[\mathrm{cfu}] / \mathrm{mL}\right)$ via a marginal ear vein beginning immediately after completion of the operation and lasting 1 hour. Group $2(n=8)$ animals were

*W. L. Gore \& Associates, Inc, Flagstaff, Ariz.
Table I. Grading scale for graft infectious vasculitis

\begin{tabular}{ll}
\hline Histologic grade & \multicolumn{1}{c}{ Definition } \\
\hline 0 & $\begin{array}{c}\text { No or little evidence of infectious vasculitis } \\
\text { of graft } \\
\text { Infectious vasculitis involving less than } 10 \% \\
\text { of the graft thickness } \\
\text { Infectious vasculitis involving } 11 \% \text { to } 25 \% \\
\text { of the graft thickness } \\
\text { Infectious vasculitis involving } 26 \% \text { to } 50 \% \\
\text { of the graft thickness } \\
\text { Infectious vasculitis involving greater than } 50 \% \\
\text { of the graft thickness }\end{array}$ \\
\hline
\end{tabular}

A histologic grading system was used to quantitate the amount of infectious vasculitis present in the infected graft.

sedated 24 hours after the operation and the same volume and concentration of $S$ aureus was infused. The $S$ aureus used throughout the experiment was a biologic control strain of $S$ aureus (strain No. 25923; American Type Culture Collection, Rockville, Md). Clonal aliquots of the original strain were used throughout the study to ensure all animals were receiving the same bacterial clone.

The animals were evaluated daily for signs of infection, dehydration, pain, and anorexia by the veterinary staff and the surgical team. All animals were observed daily for 8 weeks for clinical evidence of infection or sepsis. At the end of the 8th week both the atrial and aortic grafts were explanted along with a cuff of native tissue by means of sterile technique. The animals were then put to death by barbiturate overdose. 
Table II. Results of aortic versus left atrial appendage graft infections

\begin{tabular}{ccccccc}
\hline Pig & $\begin{array}{c}\text { Aortic } \\
\text { tissue culture }\end{array}$ & $\begin{array}{c}\text { Aortic histology } \\
\text { (grade 0-4) }\end{array}$ & $\begin{array}{c}\text { Aortic } \\
\text { infection }\end{array}$ & $\begin{array}{c}\text { LAA tissue } \\
\text { culture }\end{array}$ & $\begin{array}{c}\text { LAA histology } \\
\text { (grade 0-4) }\end{array}$ & $\begin{array}{c}\text { LAA } \\
\text { infection }\end{array}$ \\
\hline 1 & + & 4 & Positive & - & 1 & Negative \\
2 & + & 4 & Positive & - & 4 & Mixed \\
3 & + & 3 & Positive & + & 3 & Positive \\
4 & - & 1 & Negative & - & 0 & Negative \\
5 & - & 2 & Mixed & - & 2 & Mixed \\
6 & + & 3 & Positive & + & 1 & Mixed \\
7 & + & 3 & Positive & + & 3 & Mixed \\
8 & + & Positive & + & Positive \\
\hline
\end{tabular}

$L A A$, Left atrial appendage; +, positive tissue culture; -, negative tissue culture; mixed, \pm tissue culture and histologic results. Histologic and microbiologic results of graft tissue are shown. Histologic evidence of graft infection was based on a vasculitis grading scale (Table I) and microbiologic evidence of infection was based on Staphylococcus aureus only cultured from the harvested tissue.

Table III. CIDGs and CPAs

\begin{tabular}{|c|c|c|c|c|}
\hline Pig & $\begin{array}{c}\text { Graft } \\
\text { material }\end{array}$ & $\begin{array}{l}\text { Graft } \\
\text { tissue } \\
\text { culture }\end{array}$ & $\begin{array}{c}\text { Graft tissue } \\
\text { histology } \\
\text { (grade 0-4) }\end{array}$ & $\begin{array}{c}\text { Aortic } \\
\text { infection }\end{array}$ \\
\hline 1 & CIDG & + & 4 & Positive \\
\hline 2 & CIDG & - & 1 & Negative \\
\hline 3 & CIDG & - & 1 & Negative \\
\hline 4 & CIDG & - & 1 & Negative \\
\hline 5 & CIDG & - & 1 & Negative \\
\hline 6 & CIDG & - & 0 & Negative \\
\hline 7 & CPA & + & 4 & Positive \\
\hline 8 & CPA & + & 3 & Positive \\
\hline 9 & $\mathrm{CPA}$ & + & 3 & Positive \\
\hline 10 & CPA & + & 2 & Positive \\
\hline 11 & CPA & - & 1 & Negative \\
\hline 12 & CPA & - & 1 & Negative \\
\hline 13 & CPA & - & 0 & Negative \\
\hline
\end{tabular}

CIDG, Collagen-impregnated Dacron graft; $C P A$, cryopreserved allograft, +, positive tissue culture; -, negative tissue culture. Histologic and microbiologic results of graft tissue are given. Histologic evidence of graft infection was based on a vasculitis grading scale (Table I) and microbiologic evidence of infection was based on Staphylococcus aureus only cultured from the harvested tissue.

Methods of analysis. Each graft was transected and one half $(1 \times 1$-cm segment) underwent bacteriologic analysis by means of standard protocols. This involved placement of the transected graft in thioglycolate broth. The broth was examined by trained microbiology technicians. If there was any indication of bacterial growth in the media, as evidenced by the media becoming opaque, the broth was plated on a blood agar culture dish and all bacteria were identified. Microbiologic evidence of graft infection was defined as explanted graft material growing only $S$ aureus while in culture. The other one half of each graft was fixed in $10 \%$ formalin for 48 hours and then embedded in paraffin. Five-micrometer sagittal sections were mounted on glass slides, and hematoxylin and eosin staining was performed by means of standard protocols. A histologic grading system was used to quantitate the amount of infectious vasculitis present in the graft (Table I) ${ }^{18}$ A blinded, experienced pathologist (Y.D.K.) graded representative slides from each sample.
Histologic evidence of graft infection was defined as a score of 2 or higher. Graft infection was defined as both microbiologic (positive tissue cultures) and histologic (infectious vasculitis score of 2 or greater) evidence of graft infection. A mixed result was defined as one positive and one negative infectious parameter result.

Phase II: Studies comparing Dacron and aortic allograft response to bacteremia. Phase I results provided a substrate for phase II of the study, in which 13 pigs underwent identical graft operations and all received only an ascending aortic graft in an attempt to determine the ability of CPA and CIDG to resist infection. Group A $(n=6)$ animals were randomized to receive CIDG (Hemashield, Meadox Medicals, Oakland, NJ) and group B $(n=7)$ animals were randomized to receive CPA. The 7 allografts had been harvested from the ascending aorta of 3 size- and age-matched pigs and prepared/cryopreserved according to commercial protocol (Cryolife, Inc, Marietta, Ga). All animals received an infusion of the same amount $(50 \mathrm{~mL})$, concentration $(1 \times$ $10^{8} \mathrm{cfu} / \mathrm{mL}$ ), and clonal passage of $S$ aureus 24 hours after the operation. Animals were put to death 8 weeks after infusion and tissue was examined.

\section{Results}

Phase I results displayed a 100\% (8/8) mortality for group 1 animals (induced bacteremia immediately after the operation), whereas no animals in group 2 (induced bacteremia 24 hours after the operation) died $(P=.001$; as calculated by the Fisher exact test). This portion of the study also revealed that whereas $75 \%$ of the aortic grafts were consistently infected, in the same animals only $25 \%$ of the left atrial appendage grafts were infected.

The mortality during phase I of the experiment was $50 \%$ (8/16). Group 1 animals (infusion immediately after the operation) all died (6 died within hours of infusion and the other 2 died within 1 week of the infusion). All of these animals underwent an uneventful operation and then displayed respiratory (increased air- 


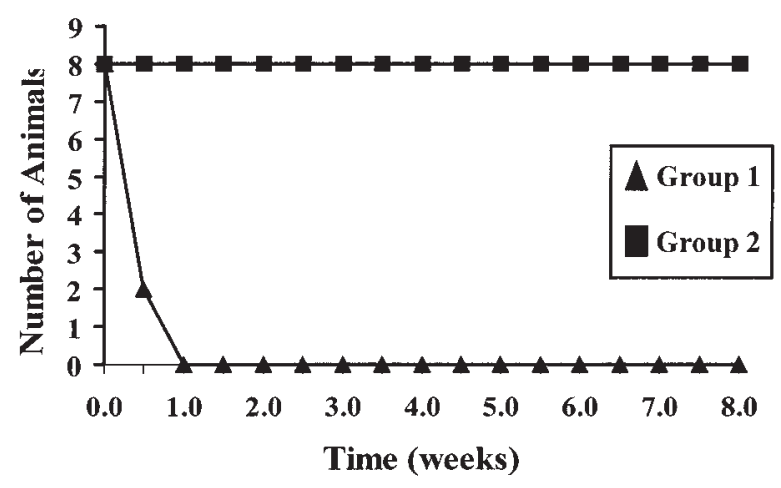

Fig 3. Graph showing comparison of survival in animals given an infusion of Staphylococcus aureus immediately after the operation (group 1) versus 24 hours after the operation (group 2).

way secretions) and cardiac (severe hypotension) complications minutes after the $S$ aureus infusion, which eventually led to death. Group 2 animals (infusion 24 hours after the operation) all survived to the end of the study without complication (Fig 3). The difference in the timing of the infusion of $S$ aureus is a significant factor of animal survival $(P=.001$, as calculated by the Fisher exact test).

Grossly, the grafts from the 8 surviving animals of group 2 displayed no evidence of aneurysmal dilation of the native aorta or grafts. These grafts were analyzed for evidence of infection (Table II). Aortic graft tissue displayed consistent histologic and microbiologic proof of infection in 6 of the 8 samples, no evidence of infection in 1 of the 8 , and a mixed result in the remaining sample. In the same 8 animals, the left atrial appendage graft material displayed consistent histologic and microbiologic proof of infection in 2 of the 8 samples, no evidence of infection in 2 of the 8 samples, and a mixed result in 4 . Both of the animals with infected left atrial appendage grafts also had infected aortic grafts. However, 4 of the 6 infected aortic grafts displayed either mixed left atrial appendage results or no evidence of infection.

Induced bacteremia performed 24 hours after surgery and the placement of graft material in the ascending aorta both appeared to be more reliable and reproducible mechanisms of graft infection.

During phase II of the experiment the mortality rate was $7.7 \%$ (1/13), with 1 animal in the CPA group (group B) dying of apparent sepsis in the 8th postoperative week. Since this animal died only days before its planned death, this animal's data were included in the study. There were consistent results between the micro-
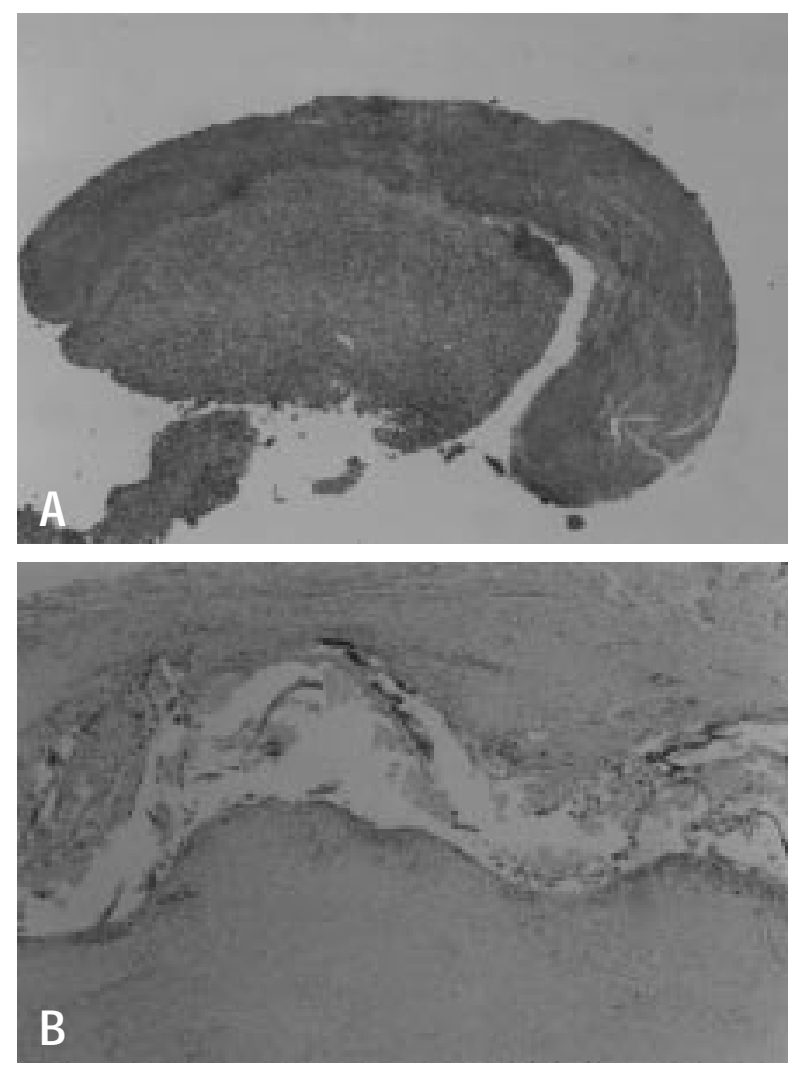

Fig 4. A, The singly infected CIDG (phase II; animal 1) displayed a significant amount of inflammatory tissue, involving more than $50 \%$ of the graft wall along with an immense lymphocytic response (vessel lumen is directed down; hematoxylin and eosin stain, magnification $40 \times$ ). B, The noninfected CIDGs displayed normal resorption of the graft, endothelialization, and minimal evidence graft inflammation (vessel lumen is directed down; hematoxylin and eosin stain, magnification $40 \times)$.

biologic and histologic grading of infection of the graft in all of the animals in phase II of the study (Table III). Grossly, there was no evidence of aneurysmal dilatation of the native aorta or graft. The overall incidence of infection was $38.5 \%$ (5/13). Infection was present in only $16.7 \%$ (1/6) in the CIDG group (group A). One animal had evidence of both tissue and histologic infection and the other 5 had neither. The single infected graft displayed an immense amount of inflammatory tissue, involving more than $50 \%$ of the graft thickness. There was also an immense lymphocytic infiltration of the graft wall (Fig 4,A). The noninfected CIDGs displayed normal resorption of the graft, endothelialization, and minimal evidence of graft or perigraft inflammation (Fig 4, B). Four (57.2\%) of the 7 animals with CPAs had infections. The animals with 

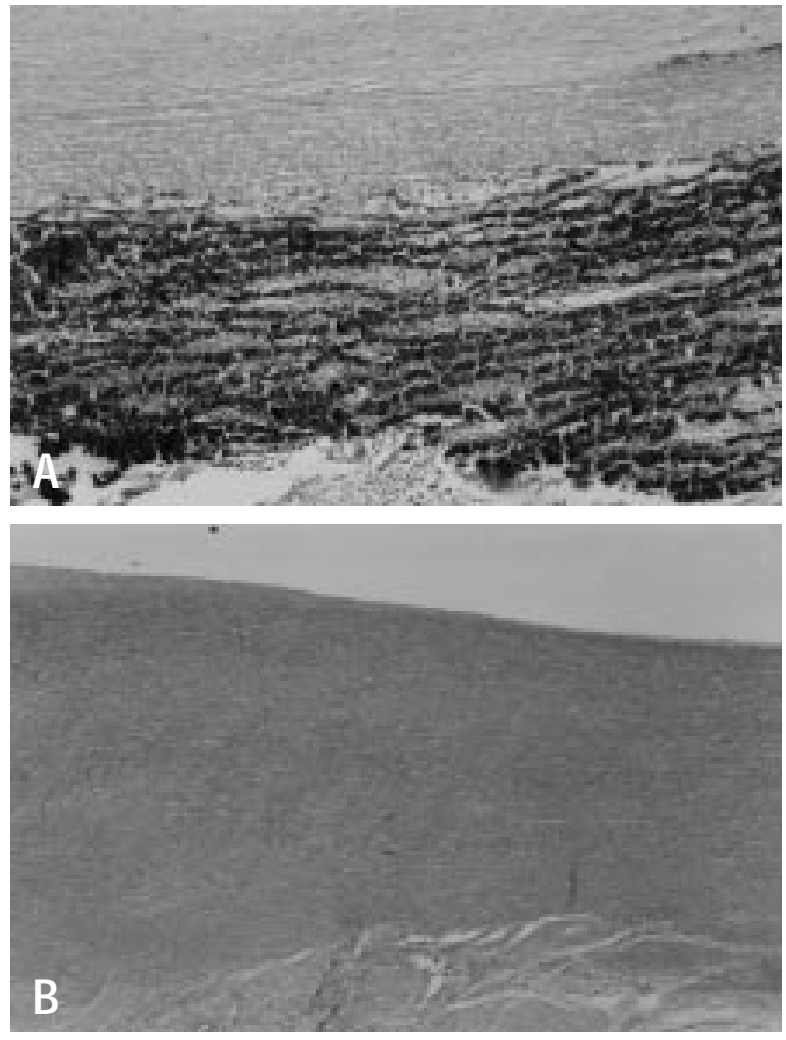

Fig 5. A, The infected cryopreserved allografts showed a significant amount of lymphocytic infiltration into the media of the graft, extending between $11 \%$ and $49 \%$ of the graft wall thickness (vessel lumen is directed down; hematoxylin and eosin stain, magnification 40×). B, The noninfected CPAs showed near normal appearing incorporation of the graft into the native aorta (vessel lumen is directed down; hematoxylin and eosin stain, magnification $40 \times$ ).

infected CPAs showed a significant amount of lymphocytic infiltration extending into the media of the graft, ranging between $11 \%$ and $49 \%$ of the graft thickness (Fig 5, A). These findings were similar to observations in the single infected graft in the CIDG group. The noninfected CPAs showed near normal appearing incorporation of the graft into the surrounding native aorta (Fig $5, B)$.

There was no significant difference between the CIDG and CPA groups in the frequency of thoracic aortic graft infections $(P=.27$, Fisher exact test) (Fig 6). The 95\% confidence intervals for the CIDG group were $2 \%$ and $46 \%$, whereas the $95 \%$ confidence intervals for the CPA group were $32 \%$ and $80 \%$. The $95 \%$ upper limit for the CIDG group (ie, 46\%) is less than the percentage shown by the CPA group (ie, 57\%), whereas the lower limit for CPA (32\%) is higher than the per-

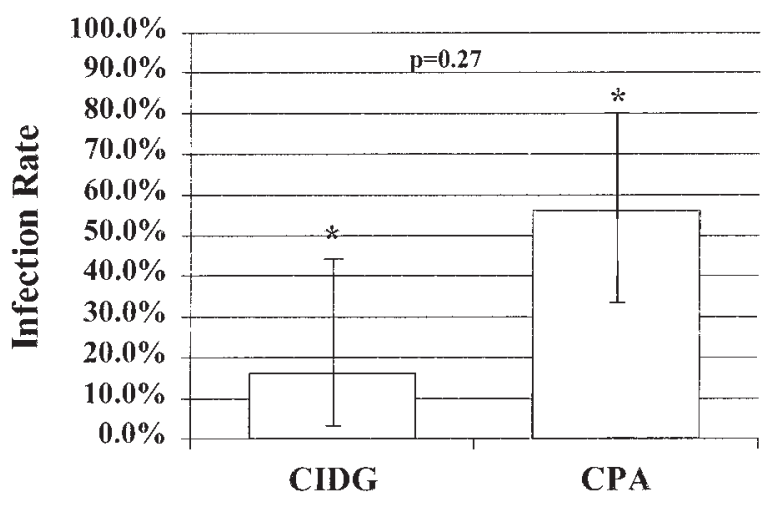

Fig 6. The infection rate of the CIDG was $16.7 \%$ whereas that of the CPA group was $57.2 \%$. There was no significant difference between the CIDG and CPA groups in the frequency of thoracic aortic graft infections $(P=.27$, Fisher exact test).

centage for the CIDG group (17\%). This indicates that CIDG is unlikely to show a higher incidence of infection than CPA and may be at least equivalent to CPA in resisting central vascular infections in the thoracic position. It also indicates a possible trend for CIDG being superior to CPA.

Furthermore, during phase II of this study we found that CIDG, infected in $16.7 \%(1 / 6)$ of animals, resists infection better than e-PTFE in the ascending aorta $(P$ $=0.047$ as calculated by logistic regression) with an odds ratio of 14.99 .

\section{Conclusions}

This study shows that the porcine model developed for the study of thoracic aortic graft infections is a reproducible model. During the course of the development of this model, we chose to study a prosthetic material, e-PTFE, because it is easily obtainable and traditionally has an incidence of infection that is higher than that of other graft materials. ${ }^{19-21}$ By using this material we were more likely to produce infection and therefore develop a model that would be able to detect more subtle differences between infection occurrences in other graft materials. We avoided having antibiotics become a confounding variable by not giving the animals perioperative antibiotics. In phase I of the study, all grafts were harvested 8 weeks after the operation, as this is the time period required for complete graft endothelialization to occur. ${ }^{16}$ It was also determined that intravenous infusion of a bolus of $S$ aureus is best accomplished 24 hours after the operation as compared with immediately after the operation to ensure survival ( $0 \%$ vs $100 \%$ mortality). This is perhaps due to the sig- 
nificant impact of both an immediate bacteremia in addition to the operation, which was too much of an insult for the animals to tolerate. These animals had an anaphylactic reaction after induced bacteremia whereas the animals undergoing delayed bacteremia all survived. Phase I of this experiment also revealed that an ascending aortic onlay graft is more susceptible to bacteremia and more reliably infected than a left atrial appendage onlay graft, since the aortic graft was consistently infected in $75 \%$ of the surviving animals whereas the left atrial appendage graft was consistently infected in only $25 \%$ of the animals. The aortic graft appeared to be a more reliable and reproducible mechanism of graft infection than the left atrial appendage graft.

In this investigation the resistance of various graft materials to infection in the ascending aorta was examined. The current data reveal that CIDG is at least equivalent, if not superior, to $\mathrm{CPA}$ in resisting bacteremia and central vascular graft infection. Additionally, in phase I of this study we found that e-PTFE graft placed in the ascending aorta and infected produced a confirmed infection in $75.0 \%(6 / 8)$ of the grafts. Furthermore, on the basis of the observed odds ratio of infection, e-PTFE is almost 15 times more likely to become infected than CIDG. This may be explained by the fact that e-PTFE is nonporous and does not allow migration of monocytes and macrophages in an attempt to prevent infection. This is unlike CIDG, which is porous and provides a collagen matrix for the influx of the body's immune response. ${ }^{22,23}$ Collagen provides a matrix for a variety of cells undergoing the healing and remodeling process. ${ }^{24}$ This includes cells involved with angiogenesis. $^{25}$ It appears that Dacron impregnated with collagen would also serve to enhance this process, which is so prevalent elsewhere in the body. There is no statistically significant difference between the prevalence of infection between e-PTFE (75.0\%) and CPA $(57.1 \%)$.

In conclusion, postoperative infections developing after the repair of cardiac structures and defects are disastrous complications. Although prosthetic graft infection occurs in less than $2 \%$ of all vascular reconstructions, the high morbidity and mortality demands a search for improved methods of prevention and therapy. ${ }^{3,4}$ Deep-seated infections after reconstructive cardiovascular surgery pose a serious morbidity and lead to the highest mortality of any of the common complications after cardiac surgery. ${ }^{2}$ Because of the low incidence of vascular graft infections, the design of clinical studies is difficult, but animal models provide a valuable tool. Until now, no animal model had been devel- oped to evaluate the ability of varying graft materials in the proximal aortic position to resist infection. As a result, much of the data are anecdotal or based on retrospective clinical series. This study reports the first reproducible animal model for the study of infections of ascending thoracic aortic grafts. With this model we demonstrated that CIDGs in the ascending aorta were equivalent (and possibly superior) to CPAs in resisting infections caused by bacteremia. This model may have implications in the study of infectious endocarditis. Finally, the results of this preliminary study support the use of this model for the study of various thoracic aortic graft materials and their response to bacteremia.

We thank Mary Nemet (Department of Microbiology, SUNY-Brooklyn) for her assistance in the preparation of the bacterial inoculum and culturing of tissue during the course of this study; Daniel Brown of W. L. Gore \& Associates, Inc (Flagstaff, Ariz), for providing the graft material used in this experiment, and Patti Dawson, $\mathrm{PhD}$, of Cryolife Incorporated (Marietta, Ga) for her technical assistance in the preparation of materials used in this study.

\section{REFERENCES}

1. Jensen LJ, Kimose HH. Prosthetic graft infections: a review of 720 arterial prosthetic reconstructions. J Thorac Cardiovasc Surg 1985;33:389-91.

2. von Segesser LK, Vogt P, Genomi M, Lachat M, Turina M. The infected aorta. J Card Surg 1997;12(2 Suppl):256-61.

3. Hargrove WC III, Edmunds LH Jr. Management of infected thoracic aortic prosthetic grafts. Ann Thorac Surg 1984;37:72-7.

4. Vogt PR, von Segesser LK, Goffin Y, Neiderhauser U, Genomi M, Kunzli A, et al. Eradication of aortic infections with the use of cryopreserved arterial homografts. Ann Thorac Surg 1996;62:640-5.

5. Abad C, Hurle A, Feijoo J, Gomez-Marrero J, Abdallah A. Total aortic arch replacement by a cryopreserved aortic arch homograft. Eur J Cardiothorac Surg 1995;9:531-3.

6. Glaziar JJ, Verwilghen J, Donaldson RM, Rose DN. Treatment of complicated prosthetic aortic valve endocarditis with annular abscess formation by homograft aortic root replacement. J Am Coll Cardiol 1991; 17:1177-82.

7. Haydock D, Barratt-Boyes BG, Macedo T, Kirklin JW, Blackstone EH. Aortic valve replacement in infective endocarditis in 108 patients. J Thorac Cardiovasc Surg 1992;103:103-9.

8. Ko W, Fantini GA. Prosthetic graft infection involving the thoracic aorta: graft excision and extra-anatomic revascularization. Cardiovasc Surg 1994;2:81-4.

9. David TE. The surgical treatment of patients with prosthetic valve endocarditis. Semin Thorac Cardiovasc Surg 1995;7:47-53.

10. Ergin MA, Raissi S, Follis F. Annular destruction in acute bacterial endocarditis. J Thorac Cardiovasc Surg 1989;97:755-63.

11. Watanabe G, Haverich A, Speier R. Surgical treatment of active infective endocarditis with paravalvular involvement. J Thorac Cardiovasc Surg 1994;107:171-7.

12. Moore WS, Rossom CT, Hall AD. Transient bacteremia: a cause of infection in prosthetic vascular grafts. Am J Surg 1969;177: 342-3. 
13. Martin LF, Harris JM, Fehr DM. Valvular prosthetic infection with Staphylococcus epidermidis: experimental study of pathogenesis and therapy. J Vasc Surg 1989;9:464-71.

14. Bennion RS, Williams RA, Wilson SE. Comparison of infectibility of vascular prosthetic material by quantitation of median infective dose. Surgery 1984;95:22-6.

15. Ricci MA, Mehran RJ, Pelsikas D, Mohamed F, Guidoin R, Marios Y, et al. Species differences in the infectability of vascular grafts. J Invest Surg 1991;4:44-52.

16. Mehran RJ, Ricci MA, Graham AM, Carter K, Syms JF. Porcine model for vascular graft studies. J Invest Surg 1991;4:37-44.

17. Cooley DA. Repair of coarctation of the thoracic aorta. In: Cooley DA, editor. Techniques in cardiac surgery. 2nd ed. Philadelphia: WB Saunders; 1984. p. 39-44.

18. Rezkella S, Kloner RA, Kharib G, Kharib R. Beneficial effects of captopril in acute coxsackievirus B3 murine myocarditis. Circulation 1991;81:1039-46.

19. Edwards WH Jr, Martin RS, Jenkins JM, Edwards WH Sr, Mulherin JL Jr. Primary graft infections. J Vasc Surg 1987;6:235-9.

20. Polterauer P, Prager M, Holzenbein T, Karner J, Kretschmer G, Schemper M. Dacron versus polytetrafluoroethylene for Y-aortic bifurcation grafts: a six-year prospective, randomized trial. Surgery 1992;111:626-33.

21. Bosman PJ, Blankestijn PJ, van der Graaf Y, Heintjes RJ, Koomans HA, Eikelboom BC. A comparison between PTFE and denatured homologous vein grafts for haemodialysis access: a prospective randomized multicentre trial. The SMASH Study Group. Study of Graft Materials in Access for Haemodialysis. Eur J Vasc Endovasc Surg 1998;16:126-32.

22. Muller KM, Dasbach G. The pathology of vascular grafts. Curr Top Pathol 1994;86:273-306.

23. Foxall TL, Auger KR, Callow AD, Libby P. Adult human endothelial cell coverage of small-caliber Dacron and polytetrafluoroethylene vascular prostheses in vitro. J Surg Res 1986;41: 158-72.

24. Adzick NS. Wound healing: biologic and clinical features. In: Sabiston DC, editor. Textbook of surgery: the biologic basis of modern surgical practice. 14th ed. Philadelphia: WB Saunders; 1997. p. 212-3

25. Steinbrech DS, Longaker MT, Mehrara BJ, Saadeh PB, Chin GS, Gerrets RP, et al. Fibroblast response to hypoxia: the relationship between angiogenesis and matrix regulation. J Surg Res 1999; 84:127-33.

\section{Discussion}

Dr Paul Kurlansky (Miami Beach, Fla). I congratulate you on tackling one of the most difficult and interesting problems in all of thoracic surgery. Your results are very troubling from a clinical point of view, because conventional wisdom in clinical studies supports the use of allograft tissue over any prosthetic tissue in terms of resistance to infection.

Have you any idea why the Hemashield graft might be more resistant to infection than the allograft in your model? Specifically, might the heightened resistance be due to something in the processing of the Hemashield graft other than just the collagen impregnation? Does this material undergo some chemical or other treatment that might make it more resistant to infection?

Dr Rowe. Thank you very much for the comment. We did debate that particular point. One of our conclusions was that the Hemashield, or the CIDG, graft may reflect, to a certain extent, native tissue. It has collagen, which allows for a matrix for the natural immune response to take effect, allows for the ingrowth of lymphocytes, and allows for the migration of the macrophages to resist infection. Thus it may be more of a physiologic graft.

I am not aware of any type of special processing techniques other than the collagen impregnation of the Dacron graft, but I can only surmise that it allows more of an immune response than PTFE, which we also evaluated.

Dr Hazim J. Safi (Houston, Tex). This presentation confirms the findings we made with the late Dr Crawford. We did not use allografts for treating graft infections. I wonder, though, whether you wrap the Dacron graft with omentum and what antibiotics you prescribe postoperatively. We continue to be very happy with the Dacron graft in cases of infection. We wrap it with omentum and prescribe lifelong antibiotic therapy.

Dr Rowe. In this particular model, we did not use an omental wrap or a vascularized pedicle graft to try to inhibit infection. The main purpose of this study was to compare the various graft materials with as minimal a number of confounding variables as possible. I am familiar with your work in the clinical setting.

The question of lifelong antibiotics is very controversial. Some centers recommend 6 weeks, 6 months, or even lifelong antibiotics, and that is a subject of controversy.

Regarding controlled studies, investigating with an animal wrap is appealing. In addition, we are looking at biomolecular markers of infection to try to detect graft infection at an earlier phase than currently available.

Dr Axel Haverich (Hannover, Germany). We developed an experimental model of thoracic aortic graft infection a few years ago, and the data were published in the Journal of Vascular Surgery. We used 4 different prosthetic grafts in the same animal, grafting the descending thoracic aorta. The Dacron material with and without collagen impregnation does accumulate the antibiotic in the graft material itself. Our concept at that time was to use a slow-release antibiotic compound, using fibrin sealant and an aminoglycoside, which was very successful.

Therefore, one of the possible explanations for your findings would be an antibiotic prophylaxis for the first 24 hours. You might actually have antibiotics concentrated in your Dacron graft, which is probably not the case with PTFE or homografts. Did you use prophylactic antibiotics intravenously?

Dr Rowe. That is a very good point. No, we did not use prophylactic antibiotics in any of our animals or in any of the settings. However, you are correct. The literature contains quite a bit of data showing that grafts impregnated with antibiotics do resist infection, prevent infection, to a much greater extent than a standard graft without the antibiotic impregnation.

Dr Timothy J. Gardner (Philadelphia, Pa). I sort of feel the spirit of Dr John Kirklin hovering back here. This is an experimental study, and the study groups did not show a sig- 
nificant difference. There is a trend, and it is a very provocative finding, but we do not have firm data here just yet.

Dr Alain Carpentier (Paris, France). Graft infection may come from the blood itself but may also come from the surrounding tissue. Have you studied or do you plan to study infection from the surrounding tissue?

Second question: You investigated Staphylococcus. Have you tried other bacteria?

Dr Rowe. Thank you very much for those comments. We proved in phase I of the study the efficacy of our model. In our model we injected bacteria systemically, and we were hoping that the bacteria would concentrate in the graft. When we put the animals to death, we did not look at other organs to see whether they were infected, but we did find consistent results with regard to the grafts themselves being infected. I suspect that these results are adequate, because the literature contains quite a bit of information showing that a graft, especially a prosthetic graft, is a potential site for bacteria to localize even 2 to 3 weeks after graft placement, so long as the graft is not endothelialized.

With regard to investigating other microbiologic agents, we did not use any agent other than $S$ aureus, because we want- ed to develop a model with one of the more commonly implicated bacteria in graft infection.

Dr John E. Mayer, Jr (Boston, Mass). One thought occurred to me in looking at your groups. What you have done is compare a porous versus a nonporous type of graft material. Certainly the homograft is nonporous in comparison with e-PTFE. Have you evaluated tissue ingrowth or vascularization in the wall of the graft? If so, is there any relationship between that and the susceptibility to infection? Certainly in almost all other models of infection the vascular supply to the tissue increases its resistance to infection.

Dr Rowe. That is actually a very insightful comment. I agree that these are 2 different types of grafts, basically porous and nonporous. I am not sure I necessarily agree with your statement that a homograft is a nonporous type of graft. I believe any graft, Dacron included and collagen included, that allows ingrowth or the native immune response to take place would resist infection. We did not evaluate vascularity, but I suspect that if the immune response were increased, the vessels would be the most probable source to transport the lymphocytes and various cells to the tissue.

\section{Online-www.aats.org}

Now you can get The Journal of Thoracic and Cardiovascular Surgery online. The Journal online brings you faster delivery time, easy searching of current and back issues, links to PubMed, AATS, WTSA and other important sites, and more. Visit the Journal online today.

\section{Receive tables of contents by e-mail}

To receive the tables of contents by e-mail, sign up through our Web site at http://www.mosby.com/jtcvs. Choose E-mail Notification. Simply type your e-mail address in the box and click the Subscription button.

Alternatively, you may send an e-mail message to majordomo@mosby.com. Leave the subject line blank and type the following as the body of your message: subscribe jtcvs_toc.

You will receive an e-mail to confirm that you have been added to the mailing list. Note that table of contents e-mails will be sent out when a new issue is posted to the Web. 